\title{
BROKEN ENGLISH DE DEREK JARMAN: EL VÍDEO MUSICAL COMO VÍA DE FINANCIACIÓN Y EXPRESIÓN
}

\author{
Ricardo Roncero Palomar \\ Universidad Rey Juan Carlos. Dpto Comunicación Audiovisual y Sociología
}

\section{Resumen}

El vídeo musical es un formato perfecto para transmitir visualmente aquellas ideas, conceptos o estéticas que acompañan al mensaje sonoro. Este artículo gira en torno al cortometraje Broken English: Three songs by Marianne Faithfull (1979), que el director británico Derek Jarman realizó para ilustrar tres canciones de la cantante. La pieza, anterior al nacimiento de la MTV, reúne tres maneras muy diferentes de enfocar un vídeo musical, como son el dominado por la presencia de la artista, el vinculado a prácticas artísticas y el vídeo protesta. Se analizará cuáles son las características visuales y qué lugar ocuparía dentro de la producción del artista británico.

\section{Palabras clave: JARMAN, DEREK (1942-1994); VÍDEO MUSICAL; CINE EXPERIMENTAL; MTV; SUPER 8}

\section{DEREK JARMAN'S BROKEN ENGLISH: MUSIC VIDEO AS A FUNDING AND EXPRESSION CHANNEL}

\section{Abstract}

Music video is a perfect tool to express visually concepts or aesthetics that accompany the sound message. This article deal around Derek Jarman's short film Broken English: Three songs by Marianne Faithfull (1979), which was created by the British director to illustrate three songs by the singer. The video, filmed before the birth of MTV, it brings together three very different ways of approaching a music video, such as the one dominated by the presence of the artist, the one linked to artistic practices and other linked with video protest. This paper shall identify their main visuals characteristics and what would its place be within the production of the British artist.

Keywords: JARMAN, DEREK (1942-1994); MUSIC VIDEO; EXPERIMENTAL CINEMA; MTV; SUPER 8

\footnotetext{
Roncero Palomar, Ricardo. 2021. "Broken English de Derek Jarman: El vídeo musical como vía de financiación y expresión". AusArt 9 (1): 235-244. DOI: 10.1387/ausart.22666
}

\section{AUSART}




\section{DEREK JARMAN Y SU CONSTELACIÓN POP}

El vídeo musical es uno de los formatos audiovisuales más consumidos por el público joven. Su importancia como producto transmisor de elementos culturales e ideológicos es patente (Illescas-Martínez 2017) y su finalidad promocional, clara. Sin embargo, estamos ante un producto del que resulta especialmente complejo y poco preciso datar su fecha concreta de nacimiento. Se trata de un formato que ha adoptado múltiples formas a lo largo de su historia y que ha sido vinculado con diferentes medios de exhibición; primero el cine, luego la televisión y, en su última adaptación, Internet. Podemos encontrar sus orígenes en algunos de los usos que se dieron a los Estudios de Oskar Fischinger durante la década de los 30 (Moritz 1995), en las piezas destinadas a los jukebox visuales de los años cuarenta, como los Soundies, o durante los sesenta con los Scopitones (Lukow 1991), en grabaciones realizadas para la televisión, como es el caso de los Snader Telescriptions producidos entre 1950 y 1953 (Herzog 2007), o en programas de variedades o musicales como The Ed Sullivan Show, American bandstand o Ready steady, Go! por citar solo algunos ejemplos. El cine musical también contribuyó a la creación del lenguaje visual del videoclip y algunas piezas del cine experimental adelantarían algunas de las características visuales más utilizadas por el formato. El caso más evidente se encuentra en la película Scorpio rising (1964) del cineasta Kenneth Anger (Sumi 2006), donde se introduce la excesiva fragmentación y la falta de continuidad temporal. A pesar de todos estos productos, que podríamos denominar protovideoclips, y que ya mantenían la esencia fundamental del formato, como mantener el punto central de atención en la interpretación de los intérpretes de la canción, no fue hasta la aparición de la MTV en 1981 cuando se estandarizó el vídeo musical como pieza clave en la promoción de un disco y se establecieron los cimientos para formar parte de una industria propia, alcanzando grandes cuotas de popularidad (Shore 1984).

El cineasta británico Derek Jarman siempre tuvo una relación de colaboración bidireccional con la música popular en general y con propuestas sonoras mas arriesgadas y minoritarias en particular. Es conocido por largos cinematográficos, como Sebastiane (1976), Caravaggio (1986), Wittgenstein (1993) o Blue (1993), aunque fue Jubilee (1978) la que tuvo especial impacto en el público joven británico. Se trata de su traducción cinematográfica a la escena punk y en ella actuaron iconos de la música como Adam Ant, Toyah Wilcox o Siouxsie Sioux. También cultivó una importante faceta como realizador de pequeñas piezas menos narrativas y de lenguaje visual más arriesgado realizadas en Super 8 en lo que sería definido como cinema of small gestures (Frey 2016), 
además de numerosos vídeos musicales, en algunos de los cuales seguía desarrollando esta faceta visualmente menos acomodada. Durante 15 años llegó a realizar más de 22 videoclips (Charlesworth 2011). También creó los fondos visuales para los conciertos de la primera gira del dúo Pet Shop Boys en 1989, mantuvo especiales relaciones con músicos como Brian Eno, que hizo composiciones específicas para varios largos, y musicalizó en su totalidad su última obra compuesta por fragmentos de sus películas en super 8 Glitterbug (1994) o con Genesis P-Orridge, ya sea en sus formaciones como Throbbing Gristles o Psychic TV, que se materializó en las interpretación visual de su música en T.G.: Psychic rally in heaven (1981) o el acompañamiento sonoro realizado para la película In the shadow of the sun (1981). Muestra de esta idea que une gran parte de la obra de Jarman con la música popular fue el proyecto fílmico que intentó desarrollar a principios de los ochenta llamado Neutron y en la que David Bowie figuraría como protagonista aunque, por temas presupuestarios, nunca llegó a realizarse (Phoenix 1999).

No todos los vídeos musicales realizados por Jarman pueden ser clasificados de la misma manera. Muchas de estas piezas son las que él define como obra alimentaria, es decir, trabajos que acepta para obtener un beneficio económico pero en los que destaca un lenguaje más homogeneizado y estándar dentro de la producción de videoclips de la época, y en los que rara vez podemos ver su huella como autor. Gran parte de estos trabajos son los que realizó para la productora Aldabra, creada en los 80 por la necesidad de producción de vídeos musicales que las nuevas cadenas de televisión solicitaban. Algunas de estas piezas como Touch de radio 'Dance', de Language (1984), Dance with me, de The Lords of the New Church (1983) o Willow weep for me, de Carmel (1983), son una prolongación de ese lenguaje visual que situaba a los músicos en el centro de atención, interpretando la canción con elementos más o menos llamativos, en el que destaca un marcado acento promocional y un patrón repetido que ya se ha visto en cientos de vídeos. El propio Jarman reconoce que no es muy bueno realizando estas piezas, y que el método de trabajo que se suele pautar no es el que suele seguir.

He estado haciendo videoclips -Dios me ayude-y no soy muy bueno en eso. Sé cómo se deben hacer, pero mi mente no funciona de esa manera -a ochenta planos por minuto-. Siempre solicito videos anteriores de los grupos, y he notado que las personas que los hacen no se identifican en absoluto con el cantante; se relacionan con algún aspecto técnico en video. Yo no tengo esa técnica; no la entiendo, y de una manera bastante deliberada me he impedido entenderla, porque me permite involucrarme con la gente 
que está frente a la cámara. Creo que en todos los videos que he hecho, la gente actúa mejor. Si el video es mejor en términos de videoclip, no lo sé. Pero consigo que sonrían y se relajen, lo que disfruto realmente. Me interesan las personas y la actuación; es una de las razones por las que me resulta difícil pensar en hacer películas más importantes. Con el video, el cantante acompaña la canción, pero con los actores no estoy seguro.

Broken English fue la primera pieza visual de promoción para una canción de música popular que Jarman realizó. Encargada en 1979 por Island Records, en esos momentos la discográfica de la cantante Marianne Faithfull, sería utilizada para promocionar el disco del mismo nombre. De 12 minutos de duración, la pieza incluía los siguientes cortes conectados entre sí: Witches song, The ballad of Lucy Jordan y Broken English. No sería la única vez que Jarman utilizara este formato en el que agrupa tres canciones en una sola pieza. Al año siguiente lo repetiría en T.G.: Psychic rally in heaven, donde suenan tres composiciones de Thobbing Gristles, aunque se podría decir que se trata más de un acompañamiento sonoro a la pieza visual y que la finalidad comercial no fue una motivación para su creación, y en 1986, con The Queen is dead para la banda británica The Smiths y que agrupa las canciones The Queen is Dead, There Is A Light That Never Goes Out y Panic. Estos trípticos visuales poseían mucha más envergadura como pieza fílmica, con un carácter menos breve que el vídeo pop convencional. Además, le permitió desarrollar diferentes experiencias visuales divididas en capítulos que marca cada canción.

La película fue realizada antes de la irrupción de la MTV, cuando las discográficas empezaron a producir vídeos, una tarea hasta entonces realizada por los programas de televisión, por lo que la estandarización del formato estaba por definir, aunque seguían vigentes las influencias de los protovideoclips. Broken English fue exhibida en cines con críticas poco positivas, como la propia Marianne indicó (2018): "en ese momento, a nadie le gustó mucho nuestra película"1. Durante muchos años la dificultad de poder ver el vídeo completo era notable, pues carecía de venta comercial, y en la televisión era más frecuente su emisión segmentada en piezas individuales, no como el tríptico original que fue concebido. No sería hasta la reedición del disco, en el año 2013, donde fue puesta a disposición del público al ser incluido como material extra tal y como Jarman la había concebido. Aunque unidos por un hilo conductor, los tres videoclips que forma parte del corto tienen distintas facturas visuales 
y sirven como ejemplo de los diferentes estilos y búsquedas de lenguajes que Derek Jarman estaba realizando en ese momento.

Este artículo va a analizar estas tres piezas, contextualizándolas con la obra más experimental del director, para saber qué grado de implicación pudo tener y de si se trata de un trabajo más vinculado con su obra artística o de una pieza con la que conseguir dinero de manera rápida (Peake 1999).

\section{2 .BROKEN ENGLISH: THREE SONGS BY MARIANNE FAITHFULL}

La película está realizada en $8 \mathrm{~mm}$ y $16 \mathrm{~mm}$, formatos amateur y semiprofesional que permitían gran libertad de rodaje al director y con el que ya había trabajado en numerosas ocasiones. Toda la pieza está conectada con un metraje extra en torno al paseo nocturno que su protagonista, Marianne Faithfull, realiza en Londres desde la catedral de San Pablo hasta la estatua de Eros en Piccadilly Circus. Comienza en blanco y negro y bajo un fuerte sonido de campanas. La cantante se dirige caminando hacia un hombre con la cabeza cubierta por una bolsa de papel con una cara dibujada. Al mirarse, comienza la música de la primera canción Witches Song y Marianne Faithfull desaparece. Esta es la pieza que más se identifica con la obra realizada anteriormente por Jarman. Se prescinde totalmente de la imagen de la cantante, elección poco habitual en la mayoría de los videoclips, lo que hace que la pieza funcione como producto aislado de la canción. Rodada en color, se pueden reconocer algunos de los elementos que más se repiten en la obra experimental de Jarman, sobre todo de la realizada en $8 \mathrm{~mm}$. Algunos de estos elementos son los pequeños espejos sostenidos por actores dirigidos a la cámara para cegar el fotómetro y conseguir oscurecer la imagen momentáneamente, presentes en piezas como The art of mirrors (1973), Sulphur (1973) o Death dance (1973), donde aparece también otro elemento reconocible más, como los personajes con bolsas de papel sobre sus cabezas que volvemos a encontrar en In the shadow of the sun. También destaca el uso visual y llamativo que hace del fuego, que está presente en el segmento que luego formaría parte de Jubilee en Jordan's dance (1977). La acción se sitúa en un muelle portuario, el tipo de entornos abandonados y semi industrializados que con frecuencia el director utilizó como escenario. Allí, un grupo de actores vestidos con máscaras inician una especie de ritual donde identificamos el primer momento de redundancia 
con respecto a la letra de la canción. Al escuchar "Formaremos el círculo, tomaremos nuestras manos y cantaremos", los personajes realizan el mismo acto. También en este momento se aprecia otra de las señas de identidad del director, la modificación en la velocidad de captación de la imagen, acelerando o reduciendo posteriormente la velocidad de proyección. La duración de los planos es considerable larga para ser un producto de este tipo, a lo que el propio Jarman hacía referencia en la cita anterior. En el segundo bloque de esta canción el espectador acude a una especie de ceremonia matrimonial. Aquí aparece el segundo punto de redundancia con la letra "Si va a haber un matrimonio, necesitamos desprecio" canta Faithfull mientras en las imágenes se muestra una ceremonia de inspiración religiosa donde el cantante Peter Robinson caracterizado como Marilyn Monroe se une con el actor Dave Baby, para terminar haciendo el amor. En esta sección, los espejos que reflejan la luz sobre el objetivo, las llamas y los hombres con bolsas en la cabeza se repiten.

Durante los últimos acordes de la canción la acción vuelve a Londres, donde se retoma la figura de Faithfull pero, esta vez, como personaje principal en el trascurso del segundo vídeo The ballad of Lucy Jordan. De nuevo en blanco y negro, la cantante pasea atenta, observando distintas escenas donde aparecen niños o una mujer limpiándose las lágrimas, en lo que parece la introducción a la melancólica historia de Lucy Jordan. Jarman juega técnicamente con la superposición de imágenes, otro de sus recursos visuales más utilizados y que usa por ejemplo en Garden of Luxor (1973), o en la ya mencionada Sulphur. Mientras los planos de la cantante continúan siendo monocromáticos, las imágenes que se superponen son en color. De esta manera, cuando en la canción se oye "Hasta que el mundo se vuelve naranja", las imágenes que se superponen a la cantante son de color naranja en lo que será la primera de las numerosas redundancias músico visuales de este segmento. Esta literalidad de la letra vertida sobre la imagen será su característica principal. Cuando en la letra escuchamos la palabra 'flores', en las imágenes aparecerán flores. Lo mismo sucede con 'coche' o 'marido', donde se presenta la imagen de un personaje masculino. Este montaje en vertical en el que se superponen imágenes de la cantante paseando con escenas de la historia de Lucy Jordan, y a pesar del uso de la superposición, se aproxima más al de la representación más común de un vídeo musical, debido a que lo escuchado en la canción aparece en imágenes y la cantante es parte central de toda la pieza.

El paseo termina en la estatua de Eros en Piccadilly Circus. La cantante se introduce en una sala de máquinas recreativas donde comienza el tercer bloque Broken English, con un nuevo cambio de registro. La canción está inspi- 
rada en la activista alemana Ulrike Meinhof (Peake 1999) y, en este caso, la pieza está formada por imágenes de archivo. Comienza con la explosión de la Bomba $\mathrm{H}$ en la isla Bikini para presentarnos un collage de found footage en el que aparece Hitler, Stalin, marchas fascistas, quemas de libros, concursos de baile, manifestaciones del Frente Nacional y un largo etcétera. Escenas sacadas de noticiarios, de distintas naturalezas y formatos que son intercaladas con el reflejo del rostro de Faithfull sobre el videojuego Space invaders. El vídeo se construye como una pieza de protesta, de denuncia en respuesta al auge del fascismo en Gran Bretaña a finales de los setenta y funciona gracias al poder visual del contenido de las imágenes. En ese caso, la huella del director no la encontramos en el uso de imágenes de archivo -que, hasta el momento, no fue destacado en su filmografía-, sino en el espíritu crítico y reivindicativo que acompañó toda su carrera de cineasta, escritor y pintor, y alrededor del cual el Museo Irlandés de Arte Moderno celebró entre 2019 y 2020 la exhibición Derek Jarman PROTEST!.

Las críticas coetáneas de la época no fueron especialmente buenas. Tildaban la pieza de sucumbir ante la literalidad de las letras de las canciones y de recurrir, en el caso del tercer bloque, a recursos visuales basados en impactantes imágenes de archivo ya vistos con anterioridad, como los dos especiales sobre rock de Tony Palmer o el documental realizado por Granada TV The Doors are open (1968) sobre The Doors (Rose 1980).

Sin embargo, ceñirse únicamente a la redundancia como criterio para definir la originalidad o no de la pieza no resulta suficiente. Otro factor que debe ser tenido en cuenta es el de la independencia de la pieza con respecto al de la canción. Aunque el propio Jarman declaraba en la entrevista con O'Prey (1984) que los videoclips tienen una gran cantidad de planos por minutos, y esta era una característica de muchos vídeos de la época, resulta muy difícil unificar el formato en base a un criterio estilístico. Sin embargo, y a pesar de esta libertad, que da como resultado propuestas más experimentales, todos los vídeos están sometidos a criterios de mercado, y es en esta parte donde se pueden encontrar piezas más independientes que otras. La canción puede existir sin vídeo, pero lo contrario no suele ser habitual. En Broken English se ha comprobado cómo, a pesar de que un segmento hace especial hincapié en la literalidad de la canción, haciendo muy complicado su visionado sin la música, otras dos -Witches song y Broken English- pueden existir sin la canción que ilustran. Su escasa redundancia con la letra y la nula o anecdótica presencia de la cantante, que en ningún momento interpreta la letra, convierte a estas piezas en dos obras totalmente autónomas. Prueba de ello es que 
varios segmentos de Witches song están incluidos en It happened by chance (Mackay 2014). Se trata de obras episódicas, realizadas por Jarman entre los años 1972 y 1983, que estaban formadas a modo de collage por varias partes de otras obras.

Derek Jarman continuó realizando vídeos musicales. El siguiente, dos años después, fue T.G.: Psychic rally in heaven, donde profundizó mucho más en la total desaparición del artista. Casi podría ser entendido como una pieza de música visual debido a la abstracción de las imágenes, conseguida por la refilmación y la velocidad de obturación prolongada de su cámara Nizo. Como si de una respuesta a su anterior pieza se tratara, las imágenes aquí se vuelven violentas, lentas, repetitivas y por momentos minimalistas; desparece cualquier tipo de belleza formal según los criterios del mercado. Una respuesta anti mercantil que costó cerca de 350 libras (Jarman 1996) y que en esta ocasión sí contó con la aceptación de la crítica, que no tardó en cuestionar aquellos vídeos musicales basados en altos presupuestos y vacuos contenidos, para ensalzar la obra conceptual de Jarman:

¿Se denuncia la base sexista y consumista de la música rock, así como se abandonan sus componentes formales? Quizás. Ciertamente, dado que los brillantes, vacíos y caros vídeos musicales, que dependen casi exclusivamente de los efectos conseguidos por su cara producción, se convierten en garantías casi automáticas de éxito en las listas (su reciente trabajo para el single Musclebound de Spandau Ballet costó aproximadamente $30.000 £$ ), la intensidad minimalista de la película de Jarman es más que bienvenida.

(Jenkins 1981)

\section{A MODO DE CONCLUSIÓN}

Es sencillo hacer una doble lectura de Broken English. Una, como obra promocional de un disco para la cantante Marianne Faithfull, y otra, como obra plástica del director Derek Jarman. En ambas lecturas, las críticas son evidentes: como producto promocional y comprendida en función de unos intereses del mercado, pueden faltar 'ganchos visuales'. Como obra de autor, la excesiva literalidad en un segmento hace que no se entienda como una pieza totalmente independiente. Sin embargo, es en esta doble versión donde encontramos la verdadera magnitud de la obra, consiguiendo introducir obra visual 
ajena a los criterios de mercado en los circuitos de exhibición del mismo. No cabe ninguna duda de que Witches song es una pieza que no solo posee las pautas estilísticas de Jarman, sino también sus temas y colaboradores, como son los personajes homosexuales que celebran una ceremonia matrimonial entre dos hombres, orquestado por un personaje inspirado en el catolicismo, mezclado con ritos paganos y varios elementos místicos. En Broke English, la pieza que acompaña la canción, el uso de las imágenes de archivo para ilustrar esa protesta en contra del auge del fascismo es brillante. La aparición de la cantante es mínima y su reflejo en la pantalla junto al videojuego Space Invaders puede ser interpretada como una metáfora de aquellos que ven en las luchas y guerras un juego o un espectáculo, como espectadores pasivos, por lo que estaría plenamente justificada. En la actualidad, la técnica del found footage forma parte de la tradición del vídeo musical y es frecuente encontrar su uso en piezas con un uso social y político, con intenciones narrativas o simplemente poético. Algunos ejemplos son Testify (2000), de Rage Against The Machine, Dayvan Cowboy (2005), de Boards of Canada o Out of Time (2003), de Blur.

La pieza más cuestionada por su gran vinculación con la letra de la canción The ballad of Lucy Jordan sigue siendo un buen ejercicio de superposición de imagen, menos sorprendente que los otros dos vídeos, pero sigue siendo un buen recurso para que la cantante comparta protagonismo con otros elementos como el color o las formas, dando como resultado algunas combinaciones formales interesantes. Cabe destacar que varios años más adelante, en 1987, Derek Jarman realizaría el videoclip In the pouring rain para Bob Geldof, en el que volvería a utilizar el mismo esquema técnico y visual presente en esta pieza, es decir, el rostro del cantante superpuesto a distintas escenas de una ciudad.

Broken English: Three songs for Marianne Faithfull no sigue el mismo esquema visual que los vídeos musicales realizados por Jarman durante la década de los 80 para la productora Aldraba, en los que la figura del cantante se sitúa en el centro de la acción y todo gira en torno a él. Esta pieza se entiende como una prolongación de la obra del artista, con sus señas de identidad reconocibles y varios de sus temas recurrentes presentes, elementos que conseguirían llegar a otro tipo de público menos familiarizado con su obra gracias a la presencia de la cantante. 


\section{Referencias bibliográficas}

Charlesworth, Michael. 2011. Derek Jarman. London: Reaktion Books

Frey, Martin. 2016. Derek Jarman: Moving picture of a painter. La Vergne TN: Ingram

Herzog, Amy. 2007. "Illustrating music: The impossible embodiments of the Jukebox film". En Medium cool: Music videos from soundies to cellphones, Roger Beebe \& Jason Middleton, eds. Durham NC: Duke University

Illescas Martínez, Jon-Emanuel. 2017. "El contenido del videoclip dominante como reproductor cultural e ideológico". Revista Mediterránea de Comunicación 2 (8): 85-104. http://hdl. handle.net/10045/67613

Jarman, Derek. 1984. 'Super 8, videos and home movies: Derek Jarman discusses 'real' film-making with Michael O'Pray”. Monthly Film Bulletin 51 (600)

Jenkins, Steve. 1981. "T.G.: Psychic rally in heaven”. Monthly Film Bulletin 48 (564)

Lukow, Gregory, 1991. "The antecedents of MTV: Soundies, scopitones and snaders, and the history of an ahistorical form". En Art of music video: Ten years after, curators, Michael Nash \& Kim Harlan Tassie, 6-8. Long Beach, CA: Long Beach Museum of Art

Mackay, James. 2014. Derek Jarman Super 8. London: Thames \& Hudson

Moritz, William. 1995. "Musique de la couleur - Cinéma intégral". En Poétique de la couleur: Une histoire du cinéma expérimental; Anthologie, sous la direction de Nicole Brenez \& Miles McKane. Paris: Auditorium du Louvre; Aix-en-Provence : Institut de I'Image

O’Pray, Michael. 1996. Derek Jarman: Dreams of England. London: British Film Institute

Peak, Tony. 1999. Derek Jarman. London: Abacus

Phoenix, Robert. 1999. "In Bowie's head: A conversation with the consummate dreamer". Gettinglt.com, 5 oct. http://gettingit.com/article/142

Rose, Cynthia. 1980. "Broken English: Three songs by Marianne Faithfull”. Monthly Film Bulletin 47 (552)

Shore, Michael. 1984. The Rolling Stone book of rock video. London: Sidgwick \& Jackson

Sumi, Glenn. 2006. "Managing anger: Kenneth Anger speaks out on phones, artistic theft and Scientology". Now Magazine, 12 oct. https://nowtoronto.com/movies/news-features/managing-anger

\section{Notas}

${ }^{1}$ Marianne Faithfull (@Faithfull_M). “And at the time, nobody really liked our film. It took a long time for people to get it, and it has become sort of a cult artwork now". Twitter, 22 oct. 2018, https://twitter.com/faithfull_m/status/1054428390374150144 